\title{
Hair Discrimination is Racist
}

\author{
Why Black Communities Advocate for Hair Peace
}

\section{JANTINA ANDERSON}

\section{SUMMARY}

Black girls are at greater risk than other girls for receiving citations due to dress code violations and talking back to teachers, as well as for much less severe behaviors, such as gum chewing, defiance, and failure to comply with prior discipline. Further, these disciplinary measures have a greater likelihood of excluding Black girls from the classroom and schools. When taking a closer look at a recent trend around the dress code policy infractions, it is clear that some policies are discriminatory, if not racist.

Black girls are being excluded from the opportunity to learn due to wearing natural hairstyles, which are common in the Black community; afros, braids, twists, and locs. As such, this brief presents recent dress code policy cases which resulted in disparaging labels and exclusionary discipline due to Black girls' natural hairstyles.

It also addresses the implications Black girls are subjected to due to the implementation, interpretation, and enforcement of said racist dress code policies.

Finally, opportunities for schools to promote awareness of different cultures which foster environments of inclusivity, growth, development, and success for all students are proposed.

\section{Author}

JANTINA ANDERSON Doctoral student in the IU School of Education at IUPUI Urban Education Studies program

These disciplinary measures have a greater likelihood of excluding Black girls from the classroom and schools. When taking a closer look at a recent trend around the dress code policy infractions, it is clear that some policies are discriminatory, if not racist. 


\section{PRESCRIBING HAIRSTYLES IS A POLITICAL ACT}

When examining school dress code policies, it is apparent they have become increasingly prescriptive. This is largely due to the early 1990s movement to address gang violence on school grounds via implementing dress code and uniform policies intended to prevent students from wearing gang attire (DaCosta, 2006; Gilbert, 1999; Mitchell-Wilson, 1998). The catalyst of this movement was a challenge made by former President Bill Clinton during his re-election campaign (Dussel, 2005). Due to the former president's encouragement and the published success of a dress code and uniform policies launched by the Long Beach, CA School District, school administrators, with the support of the national government, began implementing dress code and uniform policies across the nation (DaCosta, 2006; Gilbert, 1999; Mitchell-Wilson, 1998). With reflections of each schools' understanding and beliefs of appropriate attire and aesthetics, dress code policy language began to include guidance around clothing colors and styles, accessories, hair colors and styles, and make-up. Consequently, some students and community members voiced, and continue to voice, their concerns around the loss of students' opportunity for personal and cultural expression, and the perception of racist intent when the policies are inconsistently enforced and disparately impact students of color and more specifically, Black girls (Kim, 2014; Klein, 2013; Metler, 2017).

As noted in a report, Unlocking Opportunity for African American Girls: A Call to Action for Educational Equity, by the NAACP Legal Defense and Educational Fund, Inc. (NAACPLDF), National Women's Law Center (NWLC) (2014), Black girls are at greater risk than other girls for receiving citations due to dress code violations and talking back to teachers, as well as for much less severe behaviors such as gum chewing, defiance, and failure to comply with prior discipline. Further, a 2018 report published by the
Schools' dress code and grooming policies are negatively impacting Black girls' opportunity to learn in the classroom, socialization with their peers in academic and extracurricular settings, and outlook on their natural appearance and culturally aligned aesthetic.

NWLC, stated school dress codes in the District of Columbia (DC) promote race and gender discrimination, and create unnecessary and sometimes illegal hardship and burdens for Black girls in their school districts. As stated by a participant in the NAACPLDF and NWLCS 2014 report, "they have different rules for us [African American girls] than they do for white and Asian girls. White girls and Asian girls can wear anything and get away with it, but they will send us to the dean for wearing the same thing."

Schools' dress code and grooming policies are negatively impacting Black girls' opportunity to learn in the classroom, socialization with their peers in academic and extracurricular settings, and outlook on their natural appearance and culturally aligned aesthetic. Despite the narratives of safety and quality used by schools who utilize more prescriptive dress code policies (DaCosta, 2006), little research has been conducted to examine the implications of the policies for distinct student populations. Consequently, this policy brief discusses recent dress code policy cases which resulted in Black girls' hair being labelled as a distraction to school spaces and noncompliant with said policies. This brief also addresses the implications Black girls are subjected to due to the implementation, interpretation, and enforcement of the dress code policies. Further, efforts communities and organizations have taken to disrupt the current practices, which infringe on the boundaries of race neutral and unintentionally disparate impact, will be discussed. Finally, opportunities for schools to promote awareness of different cultures which foster environments of inclusivity, growth, 
development, and success for all students are proposed.

\section{HAIRSTYLE SEGREGATION}

While diversity, equity, and inclusion are three words that are repeatedly touted as values and a priority, schools continue to grapple with the reality of their existence within staff representation, policy language, and cultural norms. As a result, students and their communities have withstood experiences which have felt racist and exclusionary. At the center of these particular experiences were dress code policies and disciplinary practices, which excluded or reduced the opportunity to learn for young Black girls during the past seven years. Consequently, students, parents/guardians, and school communities have called out the racism and demanded space and consciousness around definitions of safety and inclusion shared by them.

Students', parents'/guardians', and community members' ideals of inclusion expand the notion of safety and quality to address and incorporate individual and cultural expressions which support the success of the student beyond academic scores (Fox, 2017; Lazar, 2017). Parents/guardians, students, and community members advocate for the mental, physical, and emotional well-being and success of the child, along with their academic scores. This broader and distinct definition of safety and quality creates the opportunity for the students to receive care and support for their whole being/self. While the concept of caring and supporting the whole child is embraced by the community, it seems to be less of a priority for the school. As a result, the dissonance between schools' definitions and enactment of and students', parents'/guardians', and communities' ideals of inclusion ebbs and flows. This conflict and tension sustain exclusionary trends around Black girls' opportunity to learn and negates space for their healthy development. Currently, Black girls are being pushed out of schools and classrooms due to their hair texture and aesthetic expressions.

Natural Black hair textures which are known to have a tighter curl pattern and more coarse texture are healthiest when worn in styles which do not require daily manipulation or harsh chemicals. As such, Black girls are embracing their personal agency to wear their hair in braids, twists, afros, locs, and wraps. While most girls are able to fully embrace this process of maturation, the freedom to choose their hair aesthetic, Black girls are met with two barriers, society's natural hair biases, and schools' adaptation and enforcement of society's hair preferences.

In 2017, Perception Institute published a hair bias study which underscored what Black women have known since arriving on the shores of North America; there is an unequivocal disdain for the hair that grows naturally from their scalp. As shown in Table 1, the "Good Hair" Study: Explicit and Implicit Attitudes Toward Black Women's Hair found that, "on average, white women show explicit bias toward black women's textured hair" (McGill-Johnson et al., 2017, p. 6).

\section{TABLE 1. AVERAGE ATTITUDES TOWARD TEXTURED HAIR - AFRO}

\begin{tabular}{|l|c|c|}
\cline { 2 - 3 } & Black Women & White Women \\
\hline Beautiful & 4.3 & 2.6 \\
Sexy/Attractive & 4.1 & 2.5 \\
Professional & 3.4 & 2.3 \\
\hline
\end{tabular}

Note: Reprinted from "The good hair study:

Explicit and implicit attitudes toward Black women's hair," by McGill-Johnson, A., Godsil, R., MacFarlane, J., Tropp, L., \& Goff, P., 2017, Perception Institute. p.7

https://perception.org/wpcontent/uploads/2017/01/TheGoodHairStudyFindingsReport.pdf 
Further the study reported a social stigma related to afro hair, "white women perceive the United States to rate the afro significantly more negatively on beauty and sexy/attractiveness than black women $(\mathrm{p}<.001)$ ". However, as shown in Figure 3, women, regardless of race, perceive the United States to view afro hair negatively as it relates to professionalism. "Black women perceive a level of social stigma against textured hair, and this perception is substantiated by white women's devaluation of natural hairstyles" (McGillJohnson et al., 2017, p. 6).

materialistic, unsuitable, and a fad have been used to describe hairstyles commonly worn in Black communities (e.g. braided extensions, cornrows, afros, locs, and twist) (Fox, 2017; Golgowski, 2013; Jacobo, 2018; Kim, 2014; Klein, 2013; Lazar, 2017; L'Heureux, 2016; Mettler, 2017; Rosenblatt, 2018; Ross, 2016).

Further, Black girls have also been burdened with exclusionary practices enacted by those in positions of power who are ideally there to protect them and ensure their academic growth and development. Conversely, as a result of their hair aesthetic choices, Black girls and their guardians have faced similar notions and actions of school segregation which existed prior to Brown v. Board of Education. Black students were forcibly excluded as a result of their race. Black girls are excluded today, because of their hair texture and/or choice in presenting it, which some say is unique to

Black girls have experienced these perceptions firsthand in their classrooms and schools, a space where protecting, nurturing, and developing the whole child should be priorities. This is exemplified in the conformance demands embedded in dress and grooming norms/policies which diminishes Black girls' space for selfexpression and healthy racial socialization identity development.

During the past seven years, incidents involving Black female students in k-12 spaces, and scrutiny around their hairstyles has increased. Black girls, ranging in age between 7 and 15, have been subjected to school leaders' and teachers' unfavorable perceptions and labeling of their hair. Terms and phrases such as distractions, their race (Crown Act, n.d.).

For example, Tiana Parker, a 7-year-old, straight A student, was told she could not attend school due to her hairstyle, dreadlocks. Deborah Brown Community School in Tulsa, OK told Tiana her hair was not "presentable" and may "distract from the respectful and serious atmosphere it strives for," (Klein, 2013). Her parents made the decision to enroll her in a new school (Golgowski, 2013).

After being harassed by students because of her natural afro, 12-year-old, Vanessa VanDyke, and her mother requested the school's assistance with addressing the peer harassment/bullying. In return, Faith Christian Academy, located in Orlando, FL, told Vanessa, her hair was a distraction and incompliant with their dress code 
policy. As a result, she received an ultimatum; one week to cut or change her hair to comply with the policy or unenroll from the academy (Huffpost Weird News, 2013). Vanessa and her mother resisted the demand to change Vanessa's hairstyle. With an overwhelming amount of national support, and publicity, in favor of Vanessa's choice, the academy allowed Vanessa to remain enrolled and wear her hair in an afro.

Fifteen-year-old twin sisters, Maya and Deanna Cook, faced in-school suspension and were excluded from the prom, track team, school bus, and faced multi-days of in-school suspension as a result of wearing long braided hair extensions, a hairstyle that is common within Black culture. After parents, community members in support of the sisters, and national media outlets reported the case, the school remained firm in their stance (Williams, 2017). However, once the attorney general's office ordered Mystic Valley Region Charter School, of Malden, MA, to stop the enforcement of their dress code policy language, the school complied.

Prior to the start of the Kentucky 2016 school year, State Legislature, Attica Scott, brought national awareness via a social media platform, Twitter, to Louisville, Kentucky's Butler Traditional High School's new dress code policy. She perceived the policy to be institutionally racist because it targeted and banned many hairstyles primarily worn by Black students; braids, cornrows, dreadlocks, or jewelry adorned hairstyles. With the support of local and national communities, and the Kentucky American Civil Liberties Union (ACLU), the policy was suspended prior to the start of the school year (L'Heureux, 2016; Ross, 2016).

In 2018, at a Roman Catholic private Louisiana school, an 11-year-old, Black girl, Faith Fennidy, was not allowed to attend classes until she removed her braided hair extensions (Rosenblatt, 2018). Christ the King Elementary School added a prohibition in their policy over the summer which banned "extensions, clip-ins or weaves" to promote natural hair. Faith's parents withdrew her from the private school (Jacobo, 2018).
Until those in positions of power are able to recognize the unnecessary burden placed on Black girls to conform to Eurocentric ideals of appropriate appearance and beauty, Black girls and women will continue to carry the associated pain and stigma of their natural hair in spaces where their appearance should be the least of their concern.

Lastly, in 2019, Marian Scott, an 8-year-old, Michigan elementary student, was not allowed to take a school picture. Paragon Charter Academy excluded Marian from taking pictures due to the red hair braided into her bun. As reported by WILX a CNN affiliate, "the Jackson, Michigan, school's handbook says students' hair color must be "of natural tones" to get their picture taken" (Buchmann, 2019, para. 2). An email sent to families, the night before picture day, outlined acceptable and prohibited picture day aesthetics and attire. Marian Scott remained enrolled in the school but stated the incident made her feel "singled out" (Sorto, 2019).

\section{INSTITUTIONAL INCLUSION, LET THEM LEARN}

Let us learn! Let them learn! These two phrases where chanted during the school board meeting in Malden, MA as community members, parents/guardians, and students gathered in support of Maya and Deanna Cook. The crowd shouted the phrase as a means to advocate for the students' rights to focus on their education versus the negative implications of violating culturally insensitive dress code policies.

Because Black girls continue to face a greater potential of school discipline and exclusion, despite the offense, a variety of organizations have led studies, commissions, and campaigns to pass policies around the disciplinary disparities and outcomes experienced by Black girls. These efforts are inclusive of but not limited Congresswoman Ayanna Presley's bill, Monique Morris' "Pushout" scholarship and advocacy efforts, and the CROWN campaign created by Dove and the CROWN coalition.

H.R. 5325 - Ending Pushout Act of 2019, proposed by Congresswoman Ayanna Pressley, was heard by the House and referred to the House 
Committee on Education and Labor on December 5, 2019 (Pressley, 2019).

Pressley's legislation, co-sponsored by Rep. Ilhan Omar (D-Minn.), would establish $\$ 2.5$ billion in new grants for states and schools to provide educators with implicit bias training, invest in counselors and social workers, and adjust school discipline policies - notably around "appearance" and "grooming" for students - with input from families and community members (Ruiz-Grossman, 2019, para. 5).

Further, the bill will create accountability for the Education Department to routinely collect additional "pushout" or exclusionary (suspensions/expulsions) discipline data and establish a task force responsible for investigating the impact of school disciplinary actions for Black and brown girls. As proposed, schools will gain eligibility for the funds created by this bill, if they ban exclusionary discipline for tardiness and absenteeism and for infractions such as dress code or grooming violations. Additionally, schools would have to eliminate corporal punishment, isolation, and restraining students (RuizGrossman, 2019).

Dr. Morris has spent the last three decades researching, writing, lecturing, and advocating on social justice issues, policies, and practices focused on improving juvenile justice, educational, and socioeconomic conditions for Black girls, women, and their families (Dr. Monique W. Morris, n.d.). In 2016, Dr. Morris' published a book titled, Pushout: The Criminalization of Black Girls in Schools, which centered the experiences that lead to the exclusion and sometimes criminalization of Black girls in school spaces (Love our Girls, n.d.). Following the release of her book, she took bringing awareness to this phenomenon one step further by releasing a documentary with the same title in 2019 (Pushout, n.d.). Further, she has partnered with Congresswoman Presley to advocate for federal
Creating spaces that acknowledge and embrace differences will serve as a model behavior and value for the students within these spaces. Ideally, the environment will translate as the norm for engaging and respecting differences beyond the classroom, and throughout each student's matriculation and maturation journeys.

legislation and programs to support the success and well-being of Black girls in school.

Finally, the National Black Women's Justice Institute (NBWJI), an organization that works to address the challenges Black girls and women face as it relates to the school to prison pipeline, employment opportunities after incarceration, and the reduction of sexual and domestic violence in Black communities was founded and is led by Dr. Morris. NBWJI publish policy recommendations, in 2019, for federal, state, and local policy makers to consider in support of addressing the alarming statistics related to Black girls' suspension, restraint, corporal punishment, law enforcement referral and arrest rates in high schools (National Black Women's Justice Institute, 2019).

To end, as it relates to the discriminatory practices of excluding and/or punishing individuals because of their hair texture, a campaign called the CROWN Act was created in 2019. The CROWN (creating a respectful and open world for natural hair) campaign was created "to ensure protection against discrimination based on race-based hairstyles by extending statutory protection to hair texture and protective styles such as braids, locs, twists, and knots in the workplace and public schools," (Crown Act About, n.d.).

To date, seven out of fifty states have passed this bill, creating race-based protection in state employment, housing, education codes for hair texture and protective styles (Crown Act About, n.d.). 


\section{CHALLENGES TO CULTURAL INCLUSION}

The efforts to understand this type of specific racism are rare. Racism is usually based on the color of one's skin which might suggest the individual's ethnic/racial heritage. Many of the current efforts that center the disproportionate rate at which some Black girls are disciplined, excluded from school spaces, and face criminal consequences do not tease apart and address the motivations for the treatment beyond students' race and gender.

The issue of Black girls wearing their natural, afro, hair is related to the disciplinary disparities but it is a much more nuanced concern. Before we can effectively discuss the policy language and efforts to enforce such dress code policies, we must first understand the reason policy makers and leaders via afro hair with such disdain and its connections to race.

The CROWN act comes the closest to exploring such nuances as it speaks more to the reasons why the definition of race should expand to include one's hair texture and styles. In order for additional states, policy makers, and leaders to buy into this connection and idea, further discussions and education around the historical, political, and social ways that hair texture and styles have been used as mediums of power most frequently used to disparage Black citizens is necessary to improve the impact of current and future proposals.

At this time, those in positions of power likely have little knowledge beyond their own experiences and understandings therefore, when students, communities, guardians advocate for inclusion they see the demand as unnecessary and their policies as neutral. They have no idea or choose to ignore the power afro hair and protective styles poses within the Black community and for those who wear them. Black girls are able to rid themselves of harmful chemicals which produce long-term health disadvantages. Black girls are also able to engage in physical sports and activities without concern around the state of their hair. Finally, Black girls are able to realize the beauty of their cultural and heritage and develop a healthy racial identity by embracing their natural texture and protective styles.

Despite the current arguments around the neutrality of the current policies and their policy maker's intentions, until those in positions of power are able to recognize the unnecessary burden placed on Black girls to conform to Eurocentric ideals of appropriate appearance and beauty, Black girls and women will continue to carry the associated pain and stigma of their natural hair in spaces where their appearance should be the least of their concern. They should have the equal opportunity to focus on learning and performing to the best of the ability without being distracted by the need to comply with a racist policy or standard. In order to reach this status, communities, parents, guardians, academics, and advocates must continue to raise this issue as a concern with the support of data and narratives to educate while advocating, and demand change.

\section{PRIORITIZE CULTURAL UNDERSTANDING}

Due to the growing racial, ethnic, religious and non-binary diversity of student bodies across the nation, consideration and familiarity of nonEurocentric, non-Christian, and non-binary cultural values and norms is necessary to construct spaces where students feel comfortable existing wholly. This comfort will provide a level of freedom to focus on learning versus being distracted by unnecessarily prescriptive, greatly oppressive, and inherently racist policies which have the propensity to traumatize those most impacted by the language and enforcement of said policies. Further, creating spaces that acknowledge and embrace differences will serve as a model behavior and value for the students within these spaces. Ideally, the environment will translate as the norm for engaging and respecting 
differences beyond the classroom, and throughout each student's matriculation and maturation journeys.

In order to achieve such spaces, policymakers and local leaders must begin building relationships with the families of the students, and become intimately familiar with the communities of the schools and student support systems. It is no longer enough for teachers and administrations to expatriate from their utopian suburbs or lifestyles each day to perform their daily role. They must become engaged school citizens who are open to, invested in, and value the culture of the students they influence and teach each day. Leaders and policy makers can achieve this by; learning the history and current landscape of the surrounding neighborhoods, meeting with nearby community organizations and organizers, conversing with school employees who live in the area, and hosting discussions with students and their families.

Further, it is also important for policy makers and local leaders to facilitate discussions with students, guardians, and parents around policies and procedures, which impact their livelihoods, prior to finalizing such rules. This may occur in the form of phone or text surveys, parent or student councils, monthly community meetings held at multiple times with virtual attendance available. Efforts of this nature will serve as a means to prioritize the understanding of cultural norms and values of their students.

Additionally, these actions will serve to better inform the decision-making process of school policies. Implications of said policies will be realized prior to the expensive lesson of a student's experienced trauma. While relationships and conversations seem to oversimplify a potential solution to this particular challenge, they are far from easy, if done with the proper intent. The potential of positive revolution which benefits all students is couched in seeking to understand and acting to include by making time, providing attention, being open to and learning differences/unique narratives/others' values, and investing in collaborative outcomes. 


\section{REFERENCES}

Buchmann, N. (2019, October 7). Eight-year-old girl denied school picture because of her hair. WILX. https://www.wilx.com/content/news/Eight-year-old-girl-denied-school-picture-because-of-her$\underline{\text { hair-562449021.html }}$

DaCosta, K. (2006). Dress code blues: An exploration of urban students' reactions to a public high School uniform policy. The Journal of Negro Education, 75(1), 49-59.

Dr. Monique W. Morris. (n.d.) Bio. https://www.moniquewmorris.me/

Dussel, I. (2005). When appearances are not deceptive: A comparative history of school uniform in Argentina and the United States (nineteenth-twentieth centuries). Paedagogica Historica, 41(1\&2), 179-195.doi:10.1080/0030923042000335538

Fox, G. (2017, May 21). After backlash, Malden school suspends controversial hair policy. The Boston Globe. https://www3.bostonglobe.com/metro/2017/05/21/trustees-malden-school-meet-overhair-policy/P0gA6z5wAT65hq84DbagmO/story.html?arc404=true

Gilbert, C. (1999). We are what we wear: Revisiting student dress codes. Brigham Young University Education and Law Journal, Summer (1), 3-18.

Golgowski, N. (2013, September 11). Oklahoma school changes dress code after 'no dreadlocks' policy sent girl home in tears. New York Daily News. https://www.nydailynews.com/news/national/oklaschool-dress-code-no-dreadlocks-policy-article-1.1452030

Huffpost Weird News. (2013, November 26). Vanessa VanDyke Could Be Expelled After Having Her Hair Mocked. Huffpost Weird News. https://www.huffpost.com/entry/vanessa-vandykeexpelled_n_4345326

Jacobo, J. (2018, August 21). 6th grader asked to leave private school over rule banning hair extensions, family says. ABC News. https://abcnews.go.com/US/6th-grader-asked-leave-private-school-rulebanning/story?id $=57311484$

Kim, C. (2014, November 27). Florida school threatens to expel student over 'natural hair'. MSNBC: The Last Word with Lawrence O’Donnell. http://www.msnbc.com/the-last-word-94 .

Klein, R. (2013, September 5). Tiana Parker, 7, switches schools after being forbidden from wearing dreads. Huffpost Black Voices. https://www.huffpost.com/entry/tiana-parkerdreads_n_3873868?guccounter $=1$

Lazar, K. (2017). Black Malden charter students punished for braided hair extensions. The Boston Globe. https://www.bostonglobe.com/metro/2017/05/11/black-students-malden-school-who-wearbraids-face-punishment-parents-say/stWDlBSCJhw1zocUWR1QMP/story.html

L'Heureux, C. (2016, August 4). Kentucky high school to change racist hair policy. The Cut. https://www.thecut.com/2016/08/kentucky-butler-traditional-high-school-dress-code-suspendsracist-hair-policy.html

Love our Girls. (n.d.). Meet Dr. Monique Morris. https://logpledge.org/meet-dr-monique-morris/ 
McGill-Johnson, A., Godsil, R., MacFarlane, J., Tropp, L., \& Goff, P. (2017). The good hair study: Explicit and implicit attitudes toward Black women's hair. Perception Institute. https://perception.org/wp-content/uploads/2017/01/TheGood-HairStudyFindingsReport.pdf

Mettler, K. (2017, May, 15). Mass. school punishes twin girls for hair braid extensions. Their parents say it's racial discrimination. The Washington Post.

https://www.washingtonpost.com/news/morning-mix/wp/2017/05/15/mass-school-punishestwins-for-hair-braid-extensions-their-parents-say-its-racialdiscrimination/?utm_term=.aac1cab1b66b

Mitchell-Wilson, A. (1998). Public school dress codes: The constitutional debate. Brigham Young University Education and Law Journal, Spring (1), 147-171.

NAACP Legal Defense \& Educational Fund, Inc. \& National Women's Law Center (2014). Unlocking opportunity for African American girls, A call to action for education equity, LDF Communications Department. https://tminstituteldf.org/wpcontent/uploads/2017/08/Unlocking-Opportunity-for-African-American-Girls_0.pdf

National Black Women's Justice Institute. (2019). End school pushout for Black girls and other girls of color. https://static.wixstatic.com/ugd/0c71ee_7d6b6469aa144b0397a4d7cd5d0f8051.pdf

Pressley, A. (2019, December 5). All Info - H.R.5325 - 116th Congress (2019-2020): Ending PUSHOUT Act of 2019. https://www.congress.gov/bill/116th-congress/house-bill/5325/all-info

Pushout Film. (n.d.) About. About $\mid$ PUSHOUT (pushoutfilm.com)

Rosenblatt, K. (2018, August 22). Louisiana girl sent home from school over braided hair extensions. NBC News. https://www.nbcnews.com/news/nbcblk/louisiana-girl-sent-home-school-over-braidedhair-extensions-n902811

Ross, A. (2016, July 28). Attica Scott: Hair policy 'stinks of racism'. Courier Journal. https://www.courierjournal.com/story/news/education/2016/07/28/attica-scott-hair-policy-institutional$\underline{\text { racism/87656240/ }}$

Ruiz-Grossman, S. (2019, December 5). Ayanna Pressley wants to stop the school-to-prison pipeline. Huffpost Politics. https://www.huffpost.com/entry/ayanna-pressley-racist-schooldiscipline_n_5de8484fe4b0d50f32ae0518

Sorto, G. (2019, October 9). An 8-year-old girl wasn't allowed to take her school picture because of her red hair extensions. CNN. https://www.cnn.com/2019/10/09/us/girl-denied-school-picture-hairtrnd/index.html

The Crown Act. (n.d.). About. About - The Official Campaign of the CROWN Act

Williams, J. (2017, May 12). War on Black hair: Wearing braids gets Black girls banned from prom at Malden charter school in Massachusetts. Newsweek. https://www.newsweek.com/wearing-braidssends-black-girls-detention-malden-charter-school- $6 \overline{08303}$ 